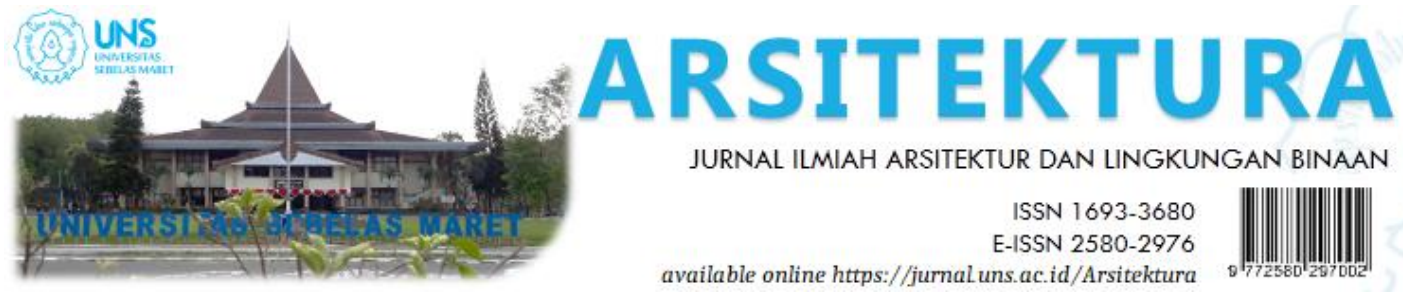

Volume 18 Issue 1 April 2020, pages:129-139

\title{
Studi Komparasi Kebertahanan Kota Pasca Bencana Alam
}

\section{City Resilience Post Natural Disaster, A Comparison Study}

\author{
June Ekawati $^{{ }^{*}}$, Gagoek Hardiman ${ }^{2}$, Edward E. Pandelaki ${ }^{3}$ \\ Program Studi Teknik Sipil, Fakultas Teknik, Universitas Yos Soedarso Surabaya, Indonesia ${ }^{{ }^{*}}$ \\ Email: juneekawati@gmail.com \\ Program Doktor Ilmu Arsitektur dan Perkotaan, Fakultas Teknik, Universitas Diponegoro, Semarang ${ }^{2}$ \\ Program Doktor Ilmu Arsitektur dan Perkotaan, Fakultas Teknik, Universitas Diponegoro, Semarang ${ }^{3}$
}

DOI: https://doi.org/10.20961/arst.v18i1.28606

Received:March 12, $2019 \quad$ Revised: October 1,2019 Accepted:October 3, $2019 \quad$ Available online: April 30, 2020

\begin{abstract}
Many cities in the world are geographically located in areas prone to natural disasters. This research is a comparative study that aims to compare the strengths, weaknesses, opportunities and challenges of these cities in the process towards a resilient city despite having a high level of vulnerability to natural disasters. Some cities which are taken as case studies here show a good level of resilience to the disasters experienced. Case studies from this study are three cities namely Kobe, in Hyogo (Japan), Padang (Indonesia) and Camalig (Philippines) which use qualitative descriptive methods with SWOT analysis techniques. From the three cases studied, it was concluded that all three have the same vulnerability due to geographical location, but these three cities also have the capacity as cities that are resilient to disasters with different strengths of capital, which are able to be counterbalanced from vulnerability to resilience.
\end{abstract}

Keywords: Natural Disasters, Survival, Vulnerability

\section{PENDAHULUAN}

\subsection{Latar Belakang}

Secara geografis, banyak kota di dunia yang ternyata berdiri di atas area yang rawan terhadap bencana. Bencana, didefinisikan sebagai peristiwa atau rangkaian peristiwa yang mengancam dan mengganggu kehidupan dan penghidupan masyarakat yang disebabkan, baik oleh faktor alam dan/atau faktor nonalam maupun faktor manusia sehingga meng-akibatkan timbulnya korban jiwa manusia, kerusakan lingkungan, kerugian harta benda, dan dampak psikologis (Undang-Undang RI Nomor 24 Tahun 2007 Tentang Penang-gulangan Bencana). Karena itu, pada dasarnya manusia itu sendiri tidak dapat mencegah terjadinya bencana, terutama bencana alam, dan hanya dapat meminimalkan dampaknya saja.

Beberapa kota dan negara di dunia seakan menjadi lokasi langganan bencana. Indonesia, Jepang, Philipina, Amerika Serikat, China dan Turki adalah sebagian di antara negara dunia yang menjadi langganan bencana. Gempa bumi, banjir dan tsunami sering menjadi penyebab timbulnya korban jiwa yang sangat besar dan kerusakan pada lingkungan terbangun. Sutopo Purwo Nugroho (Nugroho, 2016) dari BNPB menyebut bahwa kejadian bencana di dunia 
terus mengalami peningkatan dan sebanyak $76 \%$ berupa bencana hidrometeorologi (banjir, longsor, siklon tropis, kekeringan), dimana sebagian besar berdampak pada negara miskin dan sedang berkembang. Namun kota-kota di dunia mampu terus bertahan, bangkit kembali pasca bencana, bahkan bertransformasi menjadi kota yang lebih baik, lebih menarik penataan kotanya dan menjadi lokasi kunjungan wisata.

Indonesia, yang sering disebut seba-gai supermarket bencana, telah mengalami bencana yang bertubi-tubi, hampir di seluruh wilayah geografisnya (Lihat Gambar 1). Bahkan, kejadian bencana terus mengalami kecenderungan peningkatan dewasa ini. Adanya anomali cuaca dan kemarau basah menyebabkan bencana hidrometeorologi meningkat selama tahun 2016 dengan jumlah kejadian bencana sebanyak 1.495 kali. Sementara dampaknya tercatat 257 orang meninggal, 303 luka, 2,1 juta jiwa menderita /mengungsi, dan ribuan rumah rusak (Nugroho, 2016). Dari laporan UNISDR diketahui bahwa total kerugian ekonomi Indonesia akibat bencana alam di jajaran negara-negara dunia berada pada posisi ke-6 di bawah USA, Jepang, China, Rusia, dan Korea Selatan dengan jumlah kerugian 27,84 milyar USD (UNISDR dalam Alarslan, 2016). Sedangkan dalam perhitungan Bank Dunia untuk kasus bencana gempa-tsunami Aceh tahun 2004 dan gempa Yogyakarta tahun 2006 saja tercatat kerugian 7,881 jutaUSD (Tabel 1).

Tabel 1 : Perbandingan Bencana-bencana Internasional

\begin{tabular}{|c|c|c|c|c|}
\hline Negara & Bencana & $\begin{array}{l}\text { Tangg } \\
\text { al }\end{array}$ & $\begin{array}{c}\text { Jumlah } \\
\text { Korban } \\
\text { Tewas }\end{array}$ & $\begin{array}{l}\text { Kerusakan } \\
\text { \& Kerugi- } \\
\text { an (Juta } \\
\text { USD, hrga } \\
\text { 2006) }\end{array}$ \\
\hline Turki & $\begin{array}{l}\text { Gempa } \\
\text { Bumi }\end{array}$ & $\begin{array}{l}17 \mathrm{Agt} \\
1999\end{array}$ & 17.127 & 10.281 \\
\hline $\begin{array}{l}\text { Idonesia } \\
\text { (Aceh) }\end{array}$ & $\begin{array}{l}\text { Gempa\& } \\
\text { Tsunami }\end{array}$ & $\begin{array}{l}26 \text { Des } \\
2004\end{array}$ & 165.708 & 4.747 \\
\hline $\begin{array}{l}\text { Indonesia } \\
\text { (JT-Ygy) }\end{array}$ & $\begin{array}{l}\text { Gempa } \\
\text { Bumi }\end{array}$ & $\begin{array}{l}27 \text { Mei } \\
2006\end{array}$ & 5.716 & 3.134 \\
\hline Honduras & $\begin{array}{l}\text { Topan } \\
\text { Mach }\end{array}$ & $\begin{array}{l}25 \mathrm{Okt} \\
-8 \mathrm{Nov} \\
1998\end{array}$ & 14.600 & 4.698 \\
\hline $\begin{array}{l}\text { India } \\
\text { (Gujarat) }\end{array}$ & $\begin{array}{l}\text { Gempa } \\
\text { Bumi }\end{array}$ & $\begin{array}{l}26 \mathrm{Jan} \\
2001\end{array}$ & 20.005 & 2.958 \\
\hline Pakistan & $\begin{array}{l}\text { Gempa } \\
\text { Bumi }\end{array}$ & $\begin{array}{l}8 \mathrm{Okt} \\
2005\end{array}$ & 73.338 & 2.942 \\
\hline Thailand & Tsunami & $\begin{array}{l}26 \text { Des } \\
2004\end{array}$ & 8.345 & 2.345 \\
\hline Sri Lanka & Tsunami & $\begin{array}{l}26 \text { Des } \\
2004\end{array}$ & 35.399 & 1.551 \\
\hline India & Tsunami & $\begin{array}{l}26 \text { Des } \\
2004\end{array}$ & 16.389 & 1.306 \\
\hline
\end{tabular}

(Sumber : Olahan Penulis, 2019, dari Pusat

Kesiapan Bencana Asia (Asian Disaster

Preparedness Center) Thailand; ECLAC, EM-

DAC, Bank Dunia)

Bencana gempa dan tsunami di Aceh, gempa di Padang, gempa di Yogyakarta, dan bencana Lumpur panas Lapindo di Sidoarjo adalah contoh kejadian bencana besar yang terekam kuat dalam memori masyarakat Indonesia hingga kini akibat dampaknya yang begitu besar dan luas, baik dari segi jumlah korban jiwa maupun kerugian ekonomi yang dialami. Namun jika melihat perkembangan kota-kota tersebut saat ini, tentu akan dapat dilihat pula kuatnya kebertahanan kota-kota tersebut, dengan segala upaya adaptasi dan transformasi dari masyarakatnya.
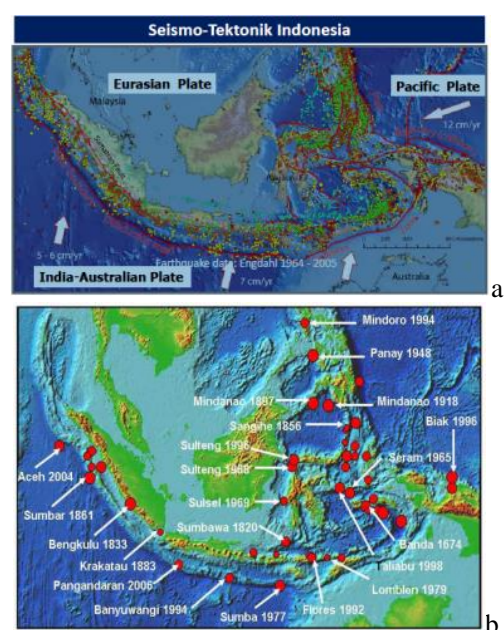

Gambar 1 : a.Seismo-Tektonik di Wilayah Indonesia ;

b. Lokasi Rawan Tsunami di Indonesia (Sumber : Nugroho, 2016)

\subsection{Permasalahan}

Sebagai negara yang secara geografis terletak di area rawan bencana, masyarakat kita banyak yang kurang menyadari kondisi kerawanan dari lokasi permukimannya. Mereka tetap menghuni daerah bantaran sungai yang rawan banjir, tepi pantai yang rawan pasang-surut dan tsunami, bahkan di lereng-lereng bukit yang rawan longsor. Faktor keamanan dalam membangun permukiman belum membudaya sehingga perlu terus dibudayakan melalui kurikulum di sekolah-sekolah maupun pelatihan mitigasi bencana hingga tingkat desa secara 
berkesinambungan. Pihak terkait seperti BNPB, BMKG maupun para akademisi juga perlu terus membangun kesadaran masyarakat akan pentingnya mitigasi bencana di daerahnya masing-masing.

Kebertahanan kota di dunia pasca bencana menjadi suatu hal yang perlu menjadi bahan diskusi untuk tujuan membangun kesadaran dan budaya keamanan terhadap permukiman kota kita. Bagaimana kita dapat mengambil pelajaran dari kota-kota yang mampu bertahan setelah diguncang bencana alam berskala besar seperti di Jepang ? Bagaimana kekuatan, kelemahan, peluang dan hambatan dari kota-kota tersebut agar bisa tetap bertahan setelah bencana ? Masyarakat perlu belajar untuk melindungi dirinya sendiri dan tidak bergantung pada bantuan pemerintah. Lewat pembudayaan, diharapkan akan muncul kearifan lokal dari masyarakat yang berada di daaerah rawan bencana sehingga dampak bencana yang dialami dapat direduksi.

\subsection{Tujuan}

Tujuan dari penyusunan artikel ini adalah untuk mengkomparasikan kekuatan, kelemahan, peluang dan hambatan dari tiap kasus bencana yang melanda kota-kota tersebut sehingga nantinya dapat diambil suatu pelajaran berharga bagi kota lain yang juga memiliki kerawanan terhadap bencana.

Penelitian dilakukan dengan studi literatur dari beberapa penelitian yang pernah dilakukan sebelumnya terhadap kota-kota yang terkena bencana. Untuk mencapai tujuan tersebut maka analisis menggunakan SWOT analysis dengan kualitatif-deskriptif.

\subsection{Kajian Literatur}

Ada lima elemen yang terkait dengan suatu peristiwa bencana bagi manusia menurut Wisner (Wisner, 2004), yaitu : Disaster, Hazards, Vulnerability, Capaci-ty and resilience serta Culture.

Dinamika konsep kebertahanan awalnya dimulai dari keprihatinan terhadap kerusakan lingkungan (ekologi) yang terjadi seperti konsep dari Holling (Holling, 1973; 1995) dan Timmerman (Timmerman, 1981).
Konsep tersebut kemudian banyak diadopsi di berbagai bidang ilmu yang lain seperti sosial dan ekonomi. World Bank (2008, dalam Nurhidayati, 2018) memandang konsep ini dari sistem manusia-ekologis yang mulai mengungkap perlunya adaptasi, menyatakan terdapat tiga karakteristik kebertahanan, yaitu : jumlah gangguan yang dapat diserap masyarakat dan masih dalam keadaan semula; sejauh mana masyarakat mampu mandiri atau menyesuaikan diri; sejauh mana masyarakat dapat membangun dan meningkatkan kapasitas untuk belajar dan beradaptasi.

Konsep lainnya tentang dikemukakan oleh IPCC dimana Kebertahanan (resilience) didefinisikan sebagai kapasitas sistem sosial, ekonomi dan lingkungan untuk mengatasi peristiwa berbahaya atau gangguan, merespon atau mereorganisasi dengan cara memperta-hankan fungsi, identitas, struktur, kapasitas untuk adaptasi, belajar dan transformasi (IPCC, 2014). Konsep ini menunjukkan kompleksnya kapasitas yang harus terlibat dalam upaya sebuah kota untuk menjadi tangguh (resilient) agar mampu bertahan dan bangkit kembali pasca tertimpa bencana.

Kerentanan yang juga menjadi konsep dalam paradigma Pengurangan Resiko Bencana (PRB), didefinisikan sebagai suatu kondisi yang sangat rawan terhadap resiko bencana dan sangat dipengaruhi oleh faktor atau proses fisik, sosial, ekonomi dan lingkungan ((Djalante \& Thomalla, 2010). Sedangkan Konsep kerentanan yang disarankan oleh IPCC (Intergovernmental panel on Climate Change) menunjukkan definisi kerentanan lingkungan sebagai fungsi dan paparan lingkungan, sensitivitas dan kapasitas adaptasi. Sensitivitas mengacu pada atribut suatu sistem, apakah manusia atau alam yang membuat lebih atau kurang rentan terhadap paparan lingkungan.

Vulnerability dan Resilience merepresentasikan dua hal yang berbeda namun memiliki keterkaitan. Karena konsep resilience dan vulnerability sangat erat hubungannya, maka faktor atau proses fisik, sosial, ekonomi dan lingkungan juga sangat mempengaruhi penilaian resilience. Untuk 
mempermudah pemahaman mengenai konsep resilience, beberapa peneliti mengemukakan bahwa resilience juga bisa didefinisikan sebagai lawan dari kerentanan (vulnerability) terhadap resiko bencana

\section{METODE}

Penelitian ini merupakan studi komparasi dengan sumber data literatur yang menggunakan metoda deskriptif kualitatif. Sedangkan analisis terhadap data yang diperoleh melalui (a) analisis deskriptif kualitatif; digunakan untuk mendeskripsikan daerah studi kasus penelitian, (b) analisis tabel, gambar dan; (c) analisis SWOT.

Adapun kota-kota yang dipilih sebagai studi kasus yaitu Kota Kobe, Padang dan Camalig, adalah kota-kota yang pernah atau sering terkena bencana alam, namun memiliki kemampuan atau kapasitas cukup baik untuk tetap bertahan dengan sumber kekuatan yang ada pada masyarakatnya.

Analisis penelitian menggunakan SWOT dengan memanfaatkan data dan beberapa gambar hasil penelitian yang mengeksplorasi kebertahanan kota pasca bencana alam maupun penelitian terkait yang telah dilakukan oleh peneliti sebelumnya, baik dengan metoda kualitatif maupun kuantitatif.

\section{PEMBAHASAN DAN ANALISIS}

\section{Kasus 1 : Kota Kobe, Hyogo, Jepang}

Jepang adalah negara yang sering menjadi destinasi favorit kunjungan wisata namun sekaligus menjadi negara yang memiliki kerawanan tinggi dalam kaitannya dengan bencana. Karena itu Jepang memiliki pengalaman kebencanaan yang sangat luas, terutama bencana gempa bumi dan tsunami yang tingkat kejadiannya sangat tinggi karena negara ini terletak pada bagian peripheral antara oceanic plate (Pacific Plate and Philippine Sea Plate) dan inland plate (gambar 3). Namun sebagaimana diketahui, kota-kota di Jepang memiliki kebertahanan yang tinggi pula terhadap ancaman bencana. Gempa berskala besar yang disebut sebagai Tokai, Tonankai dan Nankai, Japan dan Chishima Trench serta Tokyo Metro politan, telah mengakibatkan kerugian materi yang tidak sedikit (Ikeuchi \& Isago, 2007).

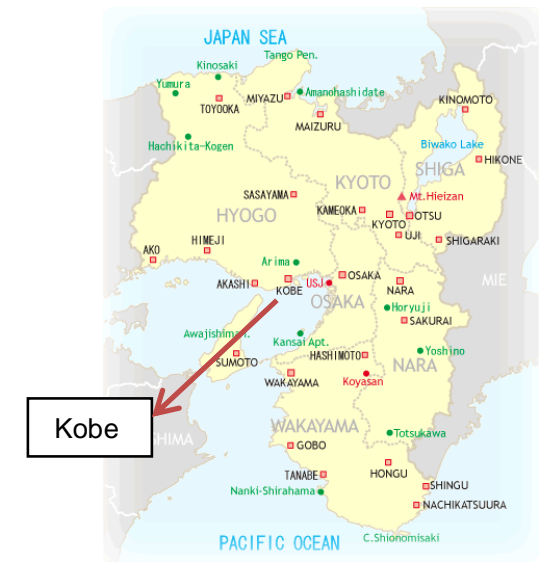

Gambar 2 : Lokasi Kota Kobe, Hyogo, di Jepang, tampak sangat rawan tsunami yang biasanya dipicu oleh gempa berskala besar Sumber:https://www.google.com/search?q=gamb $\underline{\text { ar }}+$ kota+hyogo+jepang \&safe $=$ strict $\&$ tb $=$

Kerugian besar akibat korban jiwa dan properti hingga kini yang diakibatkan banyak nya gempa berskala besar dan tsunami yang terjadi di bawah lempeng dan kondisi topografisnya, meningkatkan kesadaran akan pentingnya kebijakan nasional pemerintah Jepang untuk melindungi tanah dan kehidupan masyarakatnya dari bencana alam (Ikeuchi \& Isago, 2007). Demikian pula dengan kesadaran masyarakat Jepang akan program mitigasi bencana yang sangat baik, disertai dengan studi-studi yang terus dilakukan untuk mereduksi dampak bencana, membuat kota-kota yang rawan tersebut terlihat tangguh dengan sedikitnya jumlah korban jiwa ketika terjadi bencana.

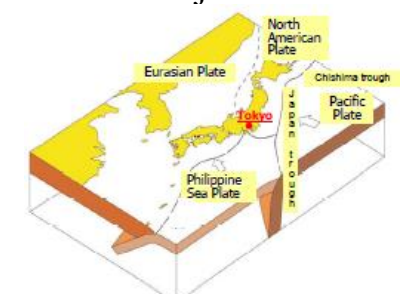

Gambar 3 : Lempeng Seismik sekitar Jepamg. Terlihat bahwa lokasi geografis Jepang sangat rawan gempa karena dikelilingi beberapa lempeng seismik, baik oceanic plate maupun inland plate (Sumber : Ikeuchi $\mathrm{K}$, Isago $\mathrm{N}, 2007$ ) 

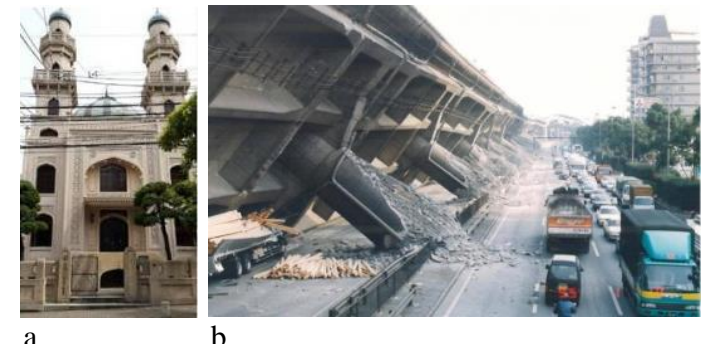

Gambar 4 : a. Bangunan mesjid tua Kobe yang bertahan dari Gempa 1995; b. Sebuah jalan layang yang terguling akibat gempa di Kobe, Jepang, 17 Januari 1995 (Sumber : https://bangka.tribunnews.com/ 2015/ 07/12/masjid-kobe-yang-tegar-dihantam-bom-dan-

gempa \& https://internasional.republika.co.id/berita/in ternasional/selarung-waktu/ojwh55366/sejarah-hari-inigempa-bumi-kobe-tewaskan-6500-orang)

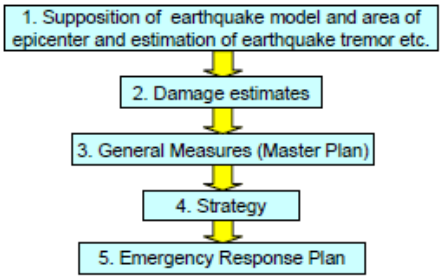

Gambar 5 : Diagram Perencanaan Gempa Berskala besar di Jepang (Sumber : Ikeuchi K \& Isago N, 2007)

Sebagai contoh adalah para peneliti Jepang yang mempelajari pendekatan baru bagi keamanan bangunan-bangunan melalui cara tradisional pada konstruksi. Walaupun Jepang berulangkali tertimpa gempa bumi, pagoda tradisionalnya yang bertingkat banyak ternyata tidak rusak (Gambar 6). Pada tahun 1995, ketika gempa Hanshin Awaji menyebabkan banyak bangunan tinggi runtuh di sekitar Kobe, pagoda berlantai 13 di Hyogo, tak jauh dari Kobe, ternyata tidak rusak dan tampak berdiri sendirian. Fiturfitur berikut membuat pagoda tangguh terhadap gempa (Atsushi, 2005, dalam (Alarslan, 2016) yaitu : (a) Materialnya berba-han dasar kayu yang memiliki elastisitas tinggi; (b) Sambungan konstruksi juga berupa kayu; (c) Konstruksi seperti kotak yang terkoneksi dari bawah ke atas; serta (d) Tiap pagoda memiliki sebuah kolom dasar yang berdiri di pusat kuil dan muncul dari lantai pertama menuju ke atas disebut Yupa yang kemudian menjadi kunci keamanan vertikal. Yupa diteguhkan di tengah-tengah dan dipertahankan oleh rantai ke struktur pagoda yang mengelili-nginya. Dalam kasus gempa bumi, hal ini memungkinkan untuk menstabilkan grup dengan membuat penyeimbang (Zatir A, Mokhtari A, Foufa A, 2014).
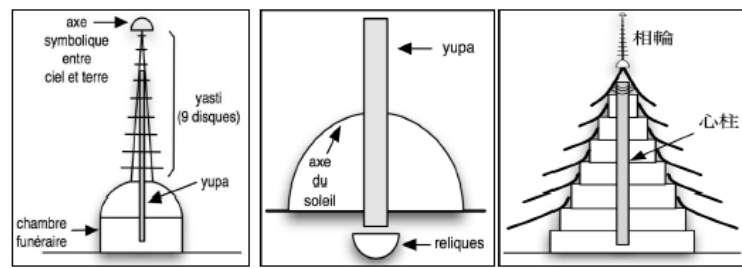

Gambar 6 : Konstruksi Pagoda di Jepang

(Sumber :Zatir, et al, 2014 )

Bukan hanya terus belajar dari kisah-kisah bencana di masa lalunya, penduduk Jepang yang menyadari kondisi negaranya yang secara geografis memang rawan bencana, terus beradaptasi dan bertran-sformasi untuk menjadi lebih baik dan selalu tanggap bencana. Beberapa langkah mitigasi bencana yang dilakukan adalah : 1) Persya-ratan bangunan yang tahan gempa untuk memastikan keamanan dan keselamatan penduduk; 2) Peringatan dini gempa di ponsel; 3) Kereta peluru (shinkansen) dengan sensor gempa; 4) Siaran TV, dimana ketika terjadi gempa akan langsung beralih ke siaran gempa; 5) Ransel darurat yang berisi peralatan dan makanan yang cukup untuk bertahan hidup selama 3-7 hari; 6) Peran Ibu Rumah Tangga yang dilatih untuk meminimal-kan korban; 7) Pelatihan di sekolah-sekolah tentang mitigasi bencana berkala; 8) Membangun terowongan penguras air senilai 3 milyar US\$ di pinggiran Tokyo yang akan membuang air banjir akibat siklon atau tsunami ke Sungai Edo (https://internasional.kompas.com/read /2018/10/02/14212651/rawan-benca na-ini-8cara-jepang-mitigasi-gempa-dan-tsunami).

\section{Kasus 2 : Kota Padang, Indonesia}

Kota Padang yang terletak di pesisir Barat Pulau Sumatra, adalah bagian dari kepulauan Nusantara yang merupakan kawasan ring of fire karena terbentuk dari tumbukan beberapa lempeng bumi utama yang kemudian bermunculan gunung api. Kota Padang merupakan dara tan memanjang dengan garis pantai sepanjang $84 \mathrm{~km}$, sehingga kondisi alam dan kehidupan masyarakatnya sangat dipengaruhi oleh 
aktivi-tas laut. Gelombang laut yang besar mampu menggerus pantainya dan menjadi ancaman di kawasan pesisir kota. Kota Padang berhadapan dengan 19 pulau kecil seperti Pulau Sikuai, Pisang Gadang dan Toran, yang konfigurasinya mampu mereduksi energi gelombang laut yang sampai ke daratan kotanya ( Lihat Gambar 7).

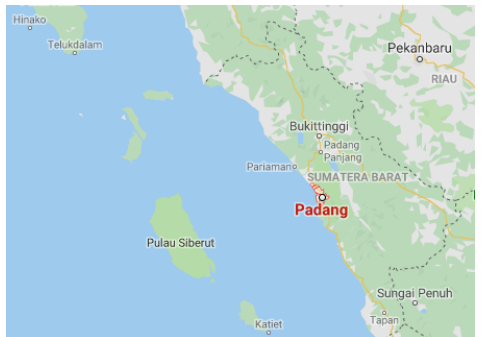

Gambar 7 : Peta Kota Padang di Propinsi Sumatra Ba-rat

Sumber : https://www.google.com/maps/place/

Padang, +Kota+Padang,+Sumatera+Barat/

Padang adalah ibukota Sumatra Barat yang secara geografis sangat rentan terhadap bencana alam tsunami dan gempa bumi. Penataan ruang pada daerah rawan gempa seperti ini memiliki peran yang sangat penting, karena bukan gempa yang menyebabkan jatuhnya banyak korban, tapi kualitas bangunan yang buruklah yang menyebabkan korban jiwa. Dengan jumlah penduduk pada Tahun 2011 sebesar 847.000 jiwa dan kepadatan 1199 jiwa per kilometer persegi (Kusumastuti, Viverita, Husodo, Suardi, \& Danarsari, 2014), kota ini memiliki kepadatan penduduk tinggi sehingga lebih rentan terhadap bencana, baik berupa bencana alam maupun non-alam.

Pada tahun 2009, terjadinya gempa bumi yang berpusat di barat daya Pariaman, Sumatera Barat, mengakibatkan jatuhnya korban jiwa, hancurnya fisik lingkungan seperti rumah dan fasilitas umum, dan kerugian sosial-ekonomi (Gambar 8a dan 8b). Akibat gempa berkekuatan 7,9 Skala Ritcher tersebut, tercatat 1.195 korban meninggal, 2 orang hilang, 619 orang luka berat, dan 1.179 orang luka ringan. Kebutuhan dana rehabilitasi dan rekonstruksi wilayah Sumatera Barat akibat gempa bumi yang terjadi pada 30 September 2009 mencapai $\mathrm{Rp}$ 6,4 triliun. (https://nasional. tempo.co/read 346475/rekonstruksi-gempa-padang-butuhrp-64-triliun).

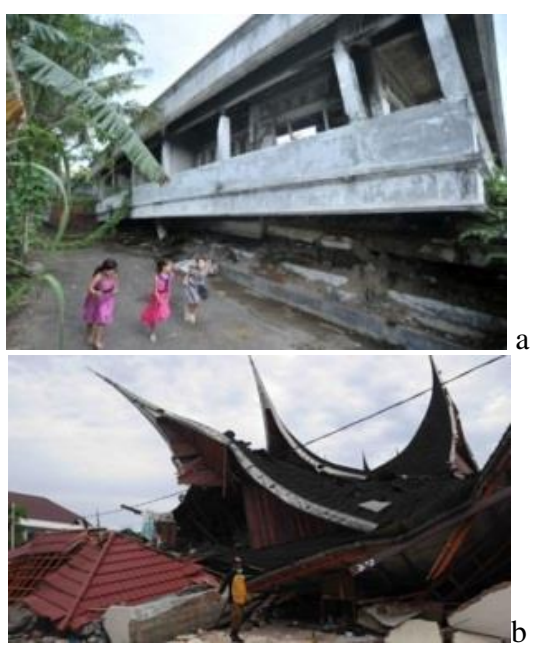

Gambar 8 : Dampak Gempa Besar tahun 2009 di Sumatra Barat terhadap Bangunan Gedung, tampak beberapa bangunan runtuh (Sumber : https://www. republika.co.id/berita/koran/kesra/16/03/06/nasional/da rah/17/09/30/oxec1428-8-tahun-gempa-padang-belajar -dari-duka \& https://nasional.tempo.co/read/346475/ rekonstruksi-gempa - padang-butuh-rp-64-triliun)

Tidak sebagaimana arsitektur tradisional Rumah Gadang yang dikatakan tahan gempa (Gambar 9), gempa kali ini, banyak mengakibatkan gedung beton bergaya arsitektur Rumah Gadang ternyata runtuh (Gambar 8b). Beberapa faktor yang kemungkinan menjadi penyebab ketidakbertahanan bangunan gedung akibat gempa Padang ini antara lain :

- Runtuhnya struktur terbawah, akibat lemahnya kolom lantai bawah (soft story effect) dimana lantai terbawah terbuka, tapi lantai di atasnya lebih kaku, dan banyak dinding pasangan bata.

- Lemahnya sambungan balok-kolom

- Mutu bahan dan pengerjaan kurang baik, tidak memiliki kekuatan cukup untuk menahan beban gravitasi dan lateral gempa yang terjadi pada struktur, sehingga struktur mudah rusak dan/atau runtuh serta menghasilkan mutu konstruksi yang buruk dan lemah. 

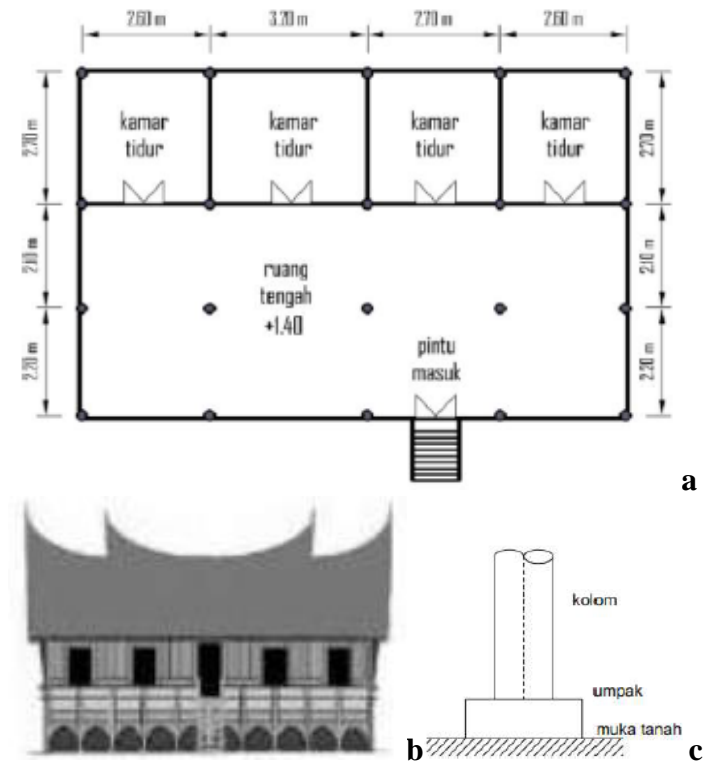

Gambar 9 : a.Denah Rumah Gadang rakyat; b.Tampak depan Rumah Gadang; c.Detail Pondasi Rumah Gadang (Sumber : Manthani, 2017)

Membangun bangunan tahan gempa tidaklah ekonomis karena prioritas utamanya adalah terciptanya bangunan yang dapat mencegah adanya korban dan memperkecil kerugian harta benda. Bangunan tahan gempa sendiri menurut Teddy (2009, dalam (Manthani, 2017) adalah: 1. Bila terjadi gempa ringan, bangunan tidak boleh mengalami kerusakan pada komponen non-struktural maupun struktu-ralnya. 2. Bila terjadi gempa sedang, bangunan boleh mengalami kerusakan pada komponen non-strukturalnya (plafond runtuh, dinding retak) akan tetapi komponen struktural (kolom, balok, sloof) tidak boleh rusak. 3. Bila terjadi gempa besar, bangunan boleh mengalami kerusakan baik pada komponen non-struktural maupun strukturalnya, akan tetapi jiwa penghuni bangunan tetap selamat, atau masih cukup waktu bagi penghuni bangun.

Untuk itu menurut Suwandojo (Siddiq, 2008), diperlukan makin masifnya penyebarluasan dan sosialisasi SNI bangunan tahan gempa yang diarahkan kepada akademisi perguruan tinggi Jurusan Sipil dan Arsitektur, konsultan dan kontraktor bangunan gedung, Anggota Asosiasi profesional seperti HAKI (Himpunan Ahli Konstruksi Indonesia) dan Para pejabat PU daerah, khususnya pengawas dan pemberi izin bangunan.

Dari segi kebertahanan kota, pada penelitian Kusumastuti dkk tentang Resilience (kebertahanan) dari kota yang rawan bencana, nilai kerentanan dari Kota Padang diperoleh dari dimensi bahaya dan ekonomi. Dimensi bahaya adalah karena Padang pernah mengalami 6 dari 7 tipe bencana alam, dan sejumlah besar kejadian bencana pada 15 tahun terakhir. Terjadinya gempa bumi pada tahun 2009 yang menyebabkan kerugian besar dan banyaknya korban jiwa, menyebabkan kota ini menjadi area yang sangat rentan terhadap bencana alam.

Adapun dalam segi kesiapsiagaan terhadap bencana untuk dimensi ekonomi, disebutkan bahwa rumah tangga di Padang relatif mampu dalam upaya pemulihan ekonominya pasca bencana. Dari segi sosial, karakter masyarakat Kota Padang dipengaruhi oleh budaya Minangkabau yang kuat dalam pola pertanian dan perdagangan, disamping kehidupan masya-rakat perkotaan modern. Karena itu kondisi ekonomi masyarakat tergolong cukup baik sehingga tingkat kebertahanan ekonominya tinggi.

Kesimpulannya : Kota Padang memi-liki kapasitas untuk mengatasi kerentanannya terhadap bencana alam. Tingkat kerentanan tinggi pada dimensi bahaya dan ekonomi disebabkan adanya event bencana gempa bumi besar pada tahun 2009 yang mengakibatkan banyaknya korban jiwa maupun harta masyarakat. Namun indeks kebertahanan yang dimiliki masih dapat diperbaiki dengan meningkatkan kesiapsiagaan (preparedness) dan/atau mereduksi kerentanannya (Kusumastuti et al, 2014).

\section{Kasus 3 : Kota Camalig, Philipina}

Lokasi studi di pedesaan Kota Camalig, berada di Provinsi Albay Philipina, yang terletak di bagian utara dan tengah kota. Daerah ini dikelilingi oleh Gunung Mayon di bagian Utara dan barangay Ilawod terletak sekitar 8-10 km dari puncak gunung, sedang barangay Tagaytay berada sekitar 10-14 km dari puncak Gunung Mayon. Barangay Ilawod relatif datar, sedangkan lahan di Tagaytay datar hingga bergelombang. 


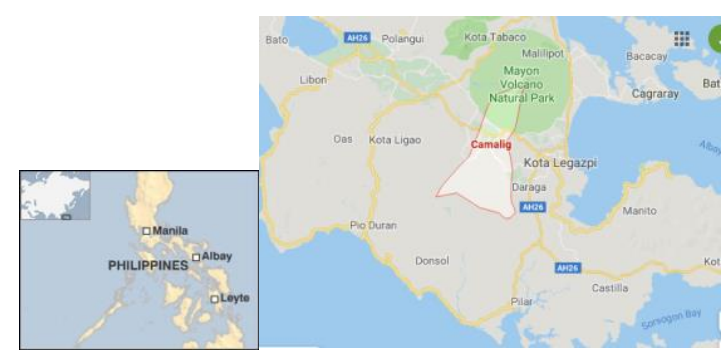

Gambar 10 : Peta Kota Camalig dan Propinsi Albay di Philipina (Sumber : https://www.bbc.com/indonesia/ duni /2011/01/110103_filipina \& https://www. Google .com/maps/place/Camalig,+Albay,+Filipina/@13.0481 $\underline{006,123.3702822,10 \mathrm{z} / \mathrm{data}=\text { ) }}$

Barangay ditempati oleh penghuni informal yaitu sekitar $60 \%$ terdiri atas rumah tangga miskin yang tidak mempunyai hak milik ataupun menyewa. Mereka bercita-cita untuk membangun mata pencaharian pertanian di daerah pedesaan di mana tekanan pada tanah kurang dan berharap bahwa mereka pada akhirnya akan memperoleh kepemilikan formal dan permanen dari tanah yang mereka tinggali secara informal (Usamah, et al, 2014).

Kohesi sosial yang menjadi kekuatan masyarakat dalam kebertahanan komunitas mereka adalah Solidaritas sosial, kontrol sosial, jaringan sosial, nilai-nilai umum dan kecintaan akan tempat dan identitas.

Persepsi komunitas yang kuat akan tingkat kebertahanan mereka akan dampak dari bencana didukung oleh domain sosial dari komunitas tersebut. Mereka membangun kebertahanan dari persepsi bahwa bencana adalah bagian dari kehidupan mereka, adanya ikatan sosial yang kuat dan kepedulian pemerintah terhadap validitas permukiman informal tersebut (Usamah, Handmer, Mitchell, \& Ahmed, 2014).

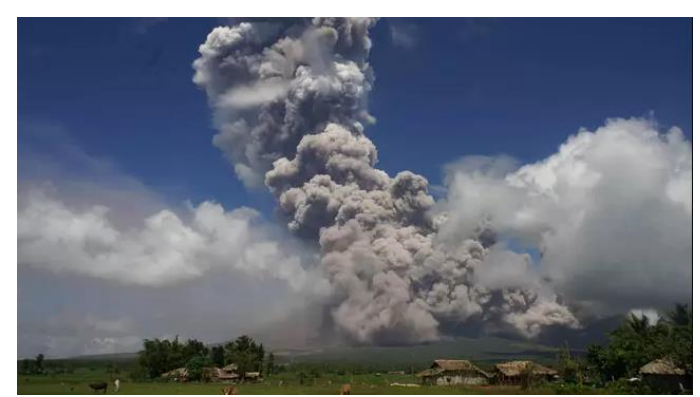

Gambar 9: Gumpalan asap dan abu vulkanis menyembur dari kawah gunung Mayon di Camalig, selatan Manila, Philipina dan beberapa bangunan di sekitarnya yang memiliki kerentanan bencana sangat tinggi (Sumber : https://www.liputan6.com/global/read 13235542/erupsi-terus-berlanjut-status-gunugmayon-filipina-siaga)

Dari penelitian ini, Usamah menye-butkan bahwa kebertahanan sosial di sini dibangun melalui kohesi sosial yang kuat, yang diperlihatkan melalui sense of community (rasa sosial) yang kuat, keper-cayaan antar anggota komunitas, keterlibatan komunitas secara aktif dan penghormatan pada budaya dan nilai-nilai yang telah ada. Dengan demikian, walaupun komunitas tersebut menghadapi kerentanan yang berhubungan dengan paparan geografis, keterbatasan ekonomi, rumah yang tidak layak dan kedudukan lahan yang tidak aman, mereka tetap percaya diri akan tangguh menghadapi bencana yang seringkali berdampak pada area tersebut.

Sebagai kesimpulan, disebutkan bahwa terdapat hubungan dan kemungkinan berdampingan yang lebih kompleks pada konsep Kebertahanan dan Kerentanan. Dalam penelitian kualitatif ini, ditemukan bahwa vulnerability dan resilience dapat eksis secara simultan, dimana orang-orang yang berada dalam kondisi rentan ternyata juga mampu resilient (tangguh, bertahan). Berkat kohesi sosial serta jaringan internalnya yang kuat, permukiman yang diasosiasikan dengan kemiskinan dan tingkat paparan bencana yang tinggi, ternyata secara potensial mampu membalikkan dan mengimbangi (counterbalance) kondisi kerentanan yang ada (Usamah et al, 2014).

\section{Analisis SWOT}

Dari ketiga studi kasus di atas, dapat dijabarkan dengan analisis SWOT untuk memetakan kekuatan, kelemahan, peluang dan tantangan dari masing-masing kasus.

\section{Strength (Kekuatan)}

Beberapa hal yang menjadi kekuatan sehingga kota-kota kasus ini mampu bertahan adalah :

○ Kobe : a) Dukungan Pemerintah terhadap program mitigasi bencana sangat kuat dengan berbagai kebijakan yang dibuat untuk melindungi keamanan dan keselamatan warganya; b) Kesadaran 
masyarakat dan akademisi untuk ikut mendukung program mitigasi sangat baik; c) Kemampuan ekonomi pemerintah dan masyarakatnya yang sangat baik membuat masa recovery pasca bencana menjadi lebih singkat.

- Padang : a) masyarakat dan elemen terkait memiliki kesiapsiagaan cukup baik sehingga periode pemulihan pasca bencana menjadi lebih singkat; b) kebertahanan ekonomi cukup baik sehingga masyarakat cepat bangkit kembali ke aktivitas sebelumnya

- Camalig : a) Kohesi sosial masyarkat sangat kuat sehingga mampu menjadi counter-balance dari kerentanan menjadi kebertahanan;

Weakness (Kelemahan)

- Kobe : Tingkat kerentanan yang tinggi karena faktor lokasi geografis

- Padang : a) tingkat kerentanan tinggi karena lokasi geografis dan kepadatan penduduk yang juga tinggi; b) pernah mengalami berbagai jenis bencana sehingga sangat beresiko

- Camalig : a) Lokasi geografis menyebabkan kerentanan tinggi; b) tingkat kerentanan dipertinggi dengan kondisi ekonomi masyarakat yang miskin; c) permukiman yang tidak layak dan status permukiman ilegal.

Opportunity (Peluang)

- Kobe : Pasca bencana, pemerintah dan masyarakat bertrasformasi kotanya menjadi lebih baik karena adanya regulasi yang lebih tanggap terhadap bencana

- Padang : Dengan bantuan para relawan dan pemerintah, masyarakat pamampu segera bangkit dan pulih kembali pasca bencana, membangun kotanya menjadi lebih baik

- Camalig : Bantuan dari berbagai kalangan dapat digunakan untuk membangun infrastruktur lingkungan menjadi lebih baik

Treat (Tantangan)

- Kobe : Perlunya alokasi dana yang lebih baik utuk pembangunan infrastruktur yang memiliki ketahanan terhadap bencana, program mitigasi bencana, dan pelatihan kepada masyarakat secara berkala
- Padang : a) biaya pembangunan kembali infrastruktur yang rusak pasca bencana sangat besar; b) perlu mambangun sarana mitigasi bencana yang memadai

- Camalig : a) Perlu membangun ekonomi masyarakat agar lebih memiiki kebertahanan terhadap bencana; b) Pemerintah perlu membuat kebijakan untuk legalisasi permukiman yang ada.

Tabel 2. Analisis SWOT

\begin{tabular}{|c|c|c|c|}
\hline & $\begin{array}{c}\text { KOBE, } \\
\text { JPG }\end{array}$ & $\begin{array}{c}\text { PADANG, } \\
\text { INA }\end{array}$ & $\begin{array}{l}\text { CAMALI } \\
\text { G, PHIL }\end{array}$ \\
\hline $\begin{array}{l}\text { STRE } \\
\text { NGTH }\end{array}$ & $\begin{array}{l}\text { o Kuatnya } \\
\text { program } \\
\text { pemerintah } \\
\text { utkmitigasi } \\
\text { bencana } \\
\text { o Kesadaran } \\
\text {, dukungan } \\
\text { masyaraka } \\
\text { t \& akade } \\
\text { misi pada } \\
\text { program } \\
\text { mitigasi } \\
\text { sangat baik } \\
\text { Kemampu } \\
\text { an } \\
\text { ekonomi } \\
\text { baik shg } \\
\text { masa reco- } \\
\text { very lebih } \\
\text { cepat }\end{array}$ & $\begin{array}{l}\text { o Memiliki } \\
\text { kapasitas } \\
\text { Kebertaha } \\
\text { nan, teru- } \\
\text { tama kesi- } \\
\text { apsiagaan } \\
\text { di bidang } \\
\text { ekonomi } \\
\text { yg cukup } \\
\text { kuat sbg } \\
\text { modal } \\
\text { pemulihan } \\
\text { o Masyaraka } \\
\text { t mampu } \\
\text { segera } \\
\text { bangkit } \\
\text { dengan } \\
\text { dukungan } \\
\text { kuat rela- } \\
\text { wan \& pe } \\
\text { merintah }\end{array}$ & $\begin{array}{l}\text { o Sense of } \\
\text { communi } \\
\text { ty \& rasa } \\
\text { saling } \\
\text { percaya } \\
\text { yg kuat } \\
\text { antar ang } \\
\text { gota ko- } \\
\text { munitas } \\
\text { o Kohesi } \\
\text { sosial yg } \\
\text { kuatmem } \\
\text { balikkan } \\
\text { kerentan- } \\
\text { an mnjdi } \\
\text { kebertah } \\
\text { anan } \\
\text { komunits } \\
\text { o Penghor } \\
\text { matan } \\
\text { masyara- } \\
\text { kat pada } \\
\text { budaya } \\
\text { dan nilai- } \\
\text { nilai yg } \\
\text { telah ada }\end{array}$ \\
\hline $\begin{array}{l}\text { WEA } \\
\text { KNES } \\
\text { S }\end{array}$ & $\begin{array}{l}\text { Kerentanan } \\
\text { tinggi krn } \\
\text { lokasi } \\
\text { geografis }\end{array}$ & $\begin{array}{l}\text { Kerentan } \\
\text { an tinggi } \\
\text { krn loka- } \\
\text { si geogra- } \\
\text { fis\&kepa } \\
\text {-datan } \\
\text { pnddknya } \\
\text { Pernah } \\
\text { mngalmi } \\
\text { brbag jnis } \\
\text { bencana } \\
\text { Krngnya } \\
\text { penget } \\
\text { masy ttg } \\
\text { kerentann } \\
\text { lokasidari }\end{array}$ & $\begin{array}{l}\text { o Lokasi } \\
\text { geografis } \\
\text { cukup } \\
\text { rentan } \\
\text { o Status } \\
\text { permuki } \\
\text { man ile- } \\
\text { gal\& kon } \\
\text { disinya } \\
\text { tdk layak } \\
\text { o Keterbata } \\
\text { san eko- } \\
\text { nomi } \\
\text { masyarak } \\
\text { atnya }\end{array}$ \\
\hline
\end{tabular}




\begin{tabular}{|c|c|c|c|}
\hline & & $\begin{array}{l}\text { bahaya } \\
\text { bencana } \\
\text { alam }\end{array}$ & \\
\hline $\begin{array}{l}\text { OPPO } \\
\text { RTUN } \\
\text { ITY }\end{array}$ & $\begin{array}{l}\text { Pembanguna } \\
\mathrm{n} \text { pasca ben- } \\
\text { cana } \\
\text { membuat } \\
\text { transfor-masi } \\
\text { kota menjadi } \\
\text { lebih baik \& } \\
\text { tangguh thd } \\
\text { bencana }\end{array}$ & $\begin{array}{l}\text { Masyarakat } \\
\text { mampu } \\
\text { segera } \\
\text { bangkit, } \\
\text { beradaptasi } \\
\text { dg dukung- } \\
\text { an relawan } \\
\& \text { pemerin } \\
\text { tah memba- } \\
\text { ngun infrast- } \\
\text { ruktukota yg } \\
\text { lebih baik }\end{array}$ & $\begin{array}{l}\text { Bantuan } \\
\text { dari } \\
\text { berbagai } \\
\text { kala ngan } \\
\text { dpt } \\
\text { membangu } \\
\text { n infra } \\
\text { struktur } \\
\text { lingkungan } \\
\text { lebih baik } \\
\text { \& tertata }\end{array}$ \\
\hline
\end{tabular}

\section{KESIMPULAN}

Dari analisis di atas, dapat diketahui adanya kesamaan pada ketiga kasus tersebut yaitu bahwa ketiganya memiliki tingkat kerentanan yang tinggi terhadap bencana terutama karena lokasi geografisnya yang terletak pada daerah rawan bencana. Namun pada masing-masing kasus memiliki kekuatan dan kapasitas yang berbeda sebagai modal untuk kebertahanan kotanya, yaitu komitmen kuat pemerintah terhadap keselamatan warga-nya dengan penerapan program maupun pelatihan berkala mitigasi bencana pada masyarakat dan aturan bangunan tahan gempa serta dukungan akademisi pada Kota Kobe, Hyogo (Jepang), kesiapsiagaan yang cukup baik terhadap kerentanan bencana pada Kota Padang (Indonesia) dan kuatnya kohesi sosial masyarakat seperti sense of community, trust dan penghormatan anggota masyarakat terhadap budaya serta nilai-nilai yang telah ada, yang dapat menjadi counterbalance dari kerentanan terhadap kebertahanan kota dari bencana alam pada Kota Camalig (Philipina). Kekuatan ini dapat menjadi pelajaran berharga bagi kota-kota lain yang juga memiliki kerentanan terhadap bencana alam, untuk dapat meningkatkan kesiapsiagaan terhadap terjadinya bencana dengan program mitigasi yang lebih baik agar nantinya mampu meminimalkan resiko atau dampak bencana alam yang dapat dialami oleh masyarakatnya.

\begin{tabular}{llcl}
\hline TREA & Perlu biaya & o Biaya ting & Membangu \\
T & besar utk & gi utk mm & n ekonomi \\
& infrastruktur & bgn kmbli & masyarakat \\
& yg rusak \& & infrastrktr & dan legiti- \\
& pendukung & rusak & masi permu \\
mitigasi & o Membang kiman yg & un kesada- & ilegal \\
bencana & ran masy \\
& sarana mi- \\
& tigasi bnca \\
& na yg lbh \\
& memadai \\
& o Pemrintah \\
& perlu me \\
& nrpkn atu- \\
& ran bngnn \\
& thn gempa \\
&
\end{tabular}

\section{UCAPAN TERIMAKASIH}

Terima kasih tak terhingga kepada rekan-rekan PDIAP 2018 Universitas Diponegoro yang telah membantu penyelesaian artikel ini, baik dalam pengumpulan data maupun penyusunannya, kakak-kakak PDIAP atas kritik dan sarannya, serta staf perpustakaan PDIAP yang telah mendukung dalam pengumpulan referensinya.

\section{REFERENSI}

Alarslan, E. (2016). Disaster resilient urban settlements in Partial Fulfillment of The Requirements For The Degree of Doctor Of Engineering ( $\mathrm{Dr}$. Ing .) IN SPATIAL PLANNING DECEMBER 2009, https://doi.org/10.17877/DE290R-248

Djalante, R., \& Thomalla, F. (2010). Community Resilience To Natural Hazards And Climate Change Impacts : A Review Of Definitions And Operational Frameworks, (January). https://doi. org/10.3850/S1793924011000952

Ikeuchi, K., \& Isago, N. (2007). Earthquake Disaster Mitigation Policy in Japan, 1-2.

Kusumastuti, R. D., Viverita, Husodo, Z. A., Suardi, L., \& Danarsari, D. N. (2014). Developing a resilience index towards natural disasters in Indonesia. International Journal of Disaster Risk Reduction, 10(PA), 327-340. https:// 
doi.org/10.1016/j.ijdrr.2014.10.007

Manthani, K. (2017). Desain dan analisis struktur bangunan adat sumatera barat terhadap ketahanan gempa (Skripsi). Departemen Teknik Sipil dan Lingkungan Fakultas Teknologi Pertanian, Institut Pertanian Bogor.

Siddiq, S. (n.d.). Bangunan tahan gempa berbasis standar nasional indonesia.

Timmerman, P. (1981). Vulnerability, Resilience and the Collapse of Society. Toronto, Canada: Institute for Environmental Studies University of Toronto, Toronto, Canada.

Usamah, M., Handmer, J., Mitchell, D., \& Ahmed, I. (2014). Can the vulnerable be resilient? Co-existence of vulnerability and disaster resilience: Informal settlements in the Philippines. International Journal of Disaster Risk Reduction, 10(PA), 178-189. https:// doi.org/10.1016/j.ijdrr.2014.08.007

Wisner, B. (2004). At Risk: Natural Hazards, (January).

Zatir A, Mokhtari A, Foufa A, Z. S. (2014). Australian Journal of Basic and Applied Sciences, 8(23), 129-135.

International Panel on Climate Change (IPCC), 2014, AR5 Synthesis Report : Climate Change 2014, https://www.ipcc.ch/ report/ar5/syr/ Diakses 01/10/2019

Pusat Kesiapan Bencana Asia (Asian Disaster Preparedness Center) Thailand; ECLAC, EM-DAC, Bank Dunia, dalam http:// siteresources.worldbank.org/INTINDO

NESIA/Resources/2262711150196584718/ExeSumBhs.pdf 